\title{
UM CASO DE ANEURYSMA CIRSOIDE DA MÃO
}

\author{
JAYME RODRIGUES
}

Doutorando

O caso de que agora nos iremos occupar, devemol-o á gentileza de nosso amigo e mestre, Dr. Bento Theobaldo Ferraz, e foi por nós observado em sua clinica, no Hospital da Beneficencia Portuguêsa.

A nossa communicação, nós o reconhecemos, péca em varios pontos; principalmente, como verão, a falta de uma arteriographia se faz sentir. Lembramos todavia, que se trata de um doente de clinica particular, e portanto, mais difficil para se submetter a certos exames indispensaveis para uma perfeita documentação scientifica. Conseguimos porém suprir em parte essa deficiencia, obtendo do doente a sua presença aqui.

Observação - P. C., branco, brasileiro, com 23 annos, solteiro, escripturario, residente nesta Capital. Entrado em : 30/8/1932.

Antecedentes hereditarios - Paes vivos, fortes. Tem 4 irmãos gozando bôa saúde. Não ha em toda sua familia caso semelhante ao seu.

Antecedentes pessoaes - Blenorrhagia, adenite inguinal bilateral. Nunca soffreu quédas nem pancadas.

Historia da molestia actual - $\mathrm{O}$ inicio de seu mal dáta de 8 annos, mais ou menos, épóca em que a raiz do annular da mão direita começou a aug entar de volume, apparecendo ahi pulsações fortes. Por essa occasiấo, quando escrevia, sentia dôr no annular direito, sentia tambem pulsações fortes ao nivel da clavicula direita, no $1 / 3$ interno.

Foi visto então pelo Dr. Bento Theob. Ferraz, tendo-lhe sido feito diagnostico de provavel aneurysma cirsoide da mão. Apresentava batimentos accentuados e fremito na sub-clavia direita. Foi-lhe instituido tratamento anti-luetico, embora houvesse negatividade da sôroreacção de Wassermann.

Deante do estado da mão, da dilatação provavel sub-clavia, e dos vasos do antebraço e braço, foi lembrada para o caso a ligadura da sub-clavia, o que foi mal recebido pela familia do paciente, com isso não concordando. 
Assim foi passando até que, a 30/8/1932, deu entrada no serviço. Soffria muito. As pulsações fortes que sentia na mão e as que se faziam na região clavicular direita, para o lado do pescoço, o atormentavam. Estava disposto a tudo, e pedia mesmo para lenitivo de seu soffrimentos que, si preciso fosse, lhe tirassem o braço.

Ao que sente, accresce ainda existencia de ausencias: dormindo púla e cae da cama.

Exame geral - Moço de bôa apparencia, bastante emotivo. Intelligencia lucida. Os pellos não apparecem em quantidade normal para a sua edade. Mucosas visiveis bem coradas. Ganglios epitrochleanos palpaveis, roliços e de regular tamanho; ganglios da cadeia inguino-crural duros e grandes. $\mathrm{Ha}$, apenas, um ganglio inguinal direito, que é doloroso á palpação. Tibialgia. Thyreoide de tamanho normal,

App. ${ }^{\circ}$ Cardio-vascular - Ictus cordis no $50^{\circ}$ espaço intercostal esquerdo. Retumbancia da 2.a bulha aortica. As demais bulhas normaes. Thrill na região lateral direita do pescoço, para o lado da porção supraclavicular. N'essa região os batimentos são accentuados. Ả ausculta, sopro systolico, melhor audivel no bordo externo do feixe clavicular do esterno-cleido-mastoideo.

A furcula esternal, embora muito projectada para traz, deixa perceber batimentos aorticos.

A arteria humeral direita, com batimentos muitos pronunciados na região supra-epitrochleana, visiveis á inspecção. Ao nivel do punho, a cubital apresenta uma dilatação, medindo $4 \times 6 \mathrm{cms}$., irregular, com thrill e sopro systolico. $\mathrm{Na}$ extremidade distal do $3 .^{\circ}$ espaço interosseo, invadindo a raiz do annular, nota-se pela face palmar a existencia de um tumor vascular pulsatil, com sopro e thrill. Com a compressão das arterias afferentes, nota-se diminuição dos tumores. Pela face dorsal da mão, na séde correspondente ha grossas veias dilatadas e salientes, tortuosas, dirigindo-se para a face dorsal do punho. De resto, todas as veias do antebraço são excessivamente dilatadas. $\mathrm{O}$ annular e minimo direitos, têm a extremidade de côr violacea. Nãa ha pérturbação da sensibilidade. A temperatura é de $35,50^{\circ}$ ha mão esquerda, e $36,7 .^{\circ}$ na direita.

Pulso radial, cheio, isochrono, batendo 80 vezes por minuto.

Pressão arterial tomada pelo $\mathrm{V}$ aquez:

Braço direito: Mx. 13 Mn. 7

* esquerdo: Mx. $12 \quad \mathrm{Mn} .7$

Radiographia em 26/8/1932 - Coração e aorta normaes. App. ${ }^{\circ}$ respiratorio - Normal. 
Revista de Medicina

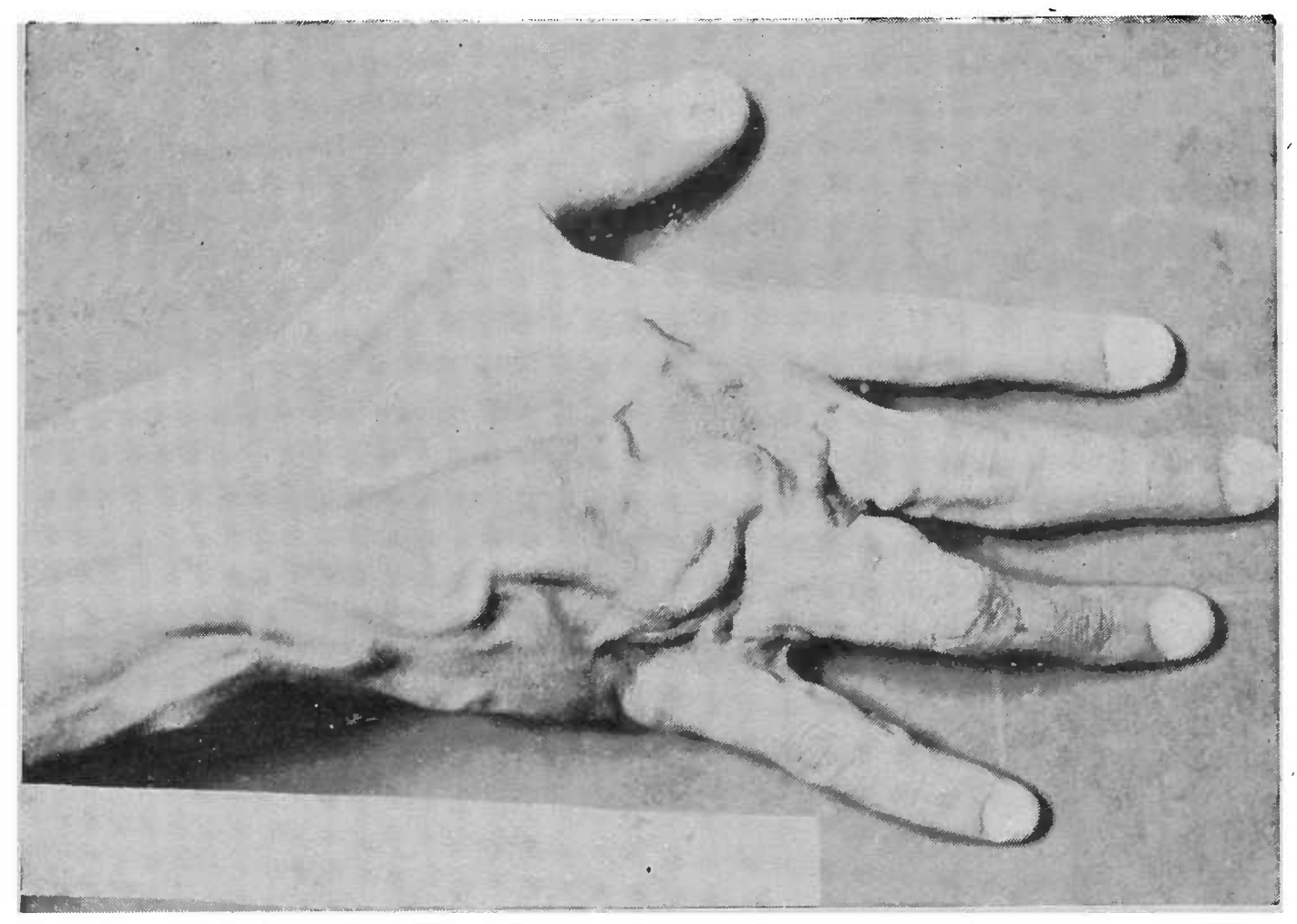

Photog. $\mathbf{n} .^{\circ} 1$

Legenda - Notar a tortuosidade e dilatação dos vasos na r'ogião dorsal. Vêr parte do tumor na raiz do annular. 

App.o digestivo e abdomen - Dôr á palpação no ponto de Mac Burney. Grande curvatura do estomago e colon transverso palpaveis. Interrogado, relata ás vezes dôres na fossa iliaca direita. Prisão de ventre e ás vezes nauseas. Figado guardando limites normaes. Baço impalpavel.

Systema nervoso - Reflexos superficiaes, profundos e reflexos pupillares conservados e normaes. Não ha Babinski nem Romberg. A sensibilidade está conservada em todas suas modalidades.

Exames de Laboratorio - Reacção de Wassermann no sôro sanguineo - Negativo.

\section{Operação em $1 / 9 / 1932$ -}

Anesthesia : Local pela sol. de novocaina adrenalinada, a $1 / 2 \% 20 \mathrm{cc}$.

Processo operatorio: Resecção do tumor da região do punho enire ligaduras; o sacco era fusiforme e media mais ou menos $3 \mathrm{cms}$. de comprimento. No plano superficial, foram feitas algumas ligaduras venosas. Sutura sub-cutanea e approximação com pontos de cat-gut N. ${ }^{\circ}$ O. Pelle com agrafes.

Durante a intervenção, o paciente teve um ataque epileptiforme de curtissima duração.

É digno de referencia o facto de, no sacco retirado, encontrar-se communicação arterio-venosa da cubital com veias proximas. Havia pequeno feixe de vasos.

Alta em 14/9/1932. Por occasião de sua sahida, as dilataçzes venosas estavam diminuidas e nâo mais se sentia o thrill no tumor da raiz do annular.

Evolução-Aos 6/10/1932, voltavá o doente a se internar no Serviço. Peorara. Parecia-lhe que as veias do dorso da mão se romperiam. De fato, apresentavam-se muito dilatadas. $O$ tumor do $3 .^{\circ}$ espaço interosseo não tinha mais thrill, apresentando pulsações mais fracas e sem sopro.

Foi resolvida nova intervenção. As possibilidades de ligadura da sub-clavia agora pareciam menores. Então, resolveu-se ligadura e seç̧ão das veias mais dilatadas na face dorsal da mão, o que foi feito immediatamente.

D'ahi a poucos dias retirava-se do Serviço um pouco melhor.

Mas a 4/12/1932, voltava, e em condições pessimas. $O$ dedo annular sentira, provavelmente a deficiencia de vascularisação: apresentava-se violaceo-escuro, com dôres intensissimas. A côr escura começara pela polpa do dedo, subindo para a raiz do mesmo. Passava pessimas noites, n'um gemer continuo. $\mathrm{O}$ que mais o incommodava era a mão. 
Operação em 15/12/1932 - Anesthesia: Local.

Processo operatorio-Desarticulação do annular direito. Retirada do tumor do 3.0 espaço inter-metacarpeano, na raiz do annular. Ligadura dos vasos e sutura em massa.

Dias após: edema no dedo medio, com dôr. Mais tarde desapparecia o edema, e o doente entrava n'um periodo de melhóra. Notava-se porém, grande a dilatação das veia no antebraço. Assim passou, até que a $25 / 12$, teve ás 16 horaa, violenta hemorrhagia no local da operação. Hemostasia de urgencia, temporaria; depois, ligadura dos vasos e sutura em massa com cat-gut N.o 2.

Dia 29/12, nova e violenta hemorrhagia semelhante em tudo á anterior. Tratamento identico.

A evolução do caso estava a pedir claramente uma nova solução. Resolveu-se agora a ligadura da radial na tabaqueira anatomica.

Operação e:n 6/1/1933-Ligadura da radial na tabaqueira.

Esta operação, como as demais, foi feita pelo Dr. Bento Ferraz.

Parece-nos trouxe grande beneficio ao doente-pelo menos temporario - .

Hoje, como poderão vêr, o seu estado é este, em linhas geraes : Batimentos expansivos na região supraclavicular direita, sem thrill nem sopro : aortite ; pressão arterial para o braço direito: $\mathrm{Mx}$. 14 e $\mathrm{Mn}$. 7, sendo Mx. 13 e Mn. 7, para o braço esquerdo. Pelle na mão direita de coloração mais escura que a esquerda. Retracção do dedo minimo direito.

$O$ que o atormenta agora são as pancadas que sente na região supraclavicular direita, a ponto de o obrigarem a dormir em decubito ventral.

Apezar d'isso, sente-se melhor do que antes.

Radiographia em 21/3/1933 - Pulmões - Espessamento do desenho vaso-bronchico no hilo direito, irradiando-se para a base ; raros nodulos de lesões antigas calcificadas.

Aorta - Medindo 2,7 cms. ao nivel da crossa em O. A. D. (dilatação media). Não ha signal radiologico do tumor comprịmindo os apices pulmonares.

Mãos - Direita - Osteoporose muito accentuada dos ossos do carpo e do metacarpo, principalmente nas epiphyses. Osteoporose intensa das phalanges, especialmente da $2 .^{a}$ phalanges do dedo médio. Amputação do annular direito.

Osteite condensante das diaphyses do $2 .^{\circ}$ e $3 .^{\circ}$ metacarpianos.

a) Paulo de Almeida Toledo 
Queremos frizar que temos insistido na therapeutica antịluetica.

Considerações - Como vêm os collegas, a historia que ouvimos em traços breves é a de um doente portador de uma affecção relativamente rara. Trata-se de um caso de aneurysma cirsoide da mão. Por si só, já bastante raro, achamol-o ainda mais interessante pelo facto de apresentar dilataçóes da aorta e provalvemente da sub-clavia direita, além dos batimentos muito fortes no braço e no antebraço. Foi esta a razão que nos levou a trazel-o a esta sessão.

Si percorrermos a litteratura, veremos que não são muitos os casos descriptos. E com o accrescimo da aortite e da provavel dilatação da sub-clavia, o caso tóma uma feição bastante particular.

Delbet relatou um caso em que as dilataçסes arteriaes acima da lesão iam até a axilla.

Habitualmente os aneurysmas cirsoides se localisam sobre o trajecto das arterias superficiaes, e de reduzido calibre. Em 70 casos reunidos, Terrier verificou serem 17 no membro superior, 6 no membro inferior, 3 no tronco e os restantes na extremidade cephalica. Encontrámos na litteratura a referencia a um caso de aneurysma cirsoide da arteria colica direita.

Facto classicamente descripto n'esta classe de aneurysmas são as multiplas communicações anormaes e faceis entre o systema arterial e venoso ao nivel dos capillares e a grande neoformáção de elementos vasculares, que suggeriu o conceito tumoral e neoplasico á escola allemã, a chamal-os "angiomas racemosos arteriaes".

Em nosso caso, como fizemos vêr durante a leitura da observação, na porção tumoral retirada na primeira intervenção, havia communicaৎ̧ão arterio-venosa. Este facto faz com que se approximem os aneurysmas cirsoides dos aneurysmas arterio-venosos. $O$ que os distingue é - facto dos aneurysmas arterio-venosos terem uma unica communicação arterio-venosa e se fazerem, no geral, em grandes vasos, ao passo que nos aneurysmas cirsoides, essa communicação é multipla e se faz em vasos de pequeno calibre.

O aneurysma cirsoide se caracteriza: $1^{\circ}$ ) alteração das arterias e arteriolas afferentes (dilatação, alongamento e flexuosidade) ; $2 .^{\circ}$ ) alteração das veias e venulas efferentes (dilatação, espessamento hypertrophico) ; $\left.3 .^{\circ}\right)$ dilatação da rede capillar intermediaria, e communicação anormalmente larga entre os systemas arterial e venoso.

Os aneurysmas cirsoides reconhecem sua origem n'um traumatismo, ou são consecutivos a um angioma arterial, segundo rezam os tratados classicos de Pathologia Cirurgica.

Jacques Reverdin apresentou ao Congresso Francês de Cirurgia de Paris, em 1897, um caso de aneurysma cirsoide de origem infecciosa. Basy um, em que era consequente a um phlegmão da mão. 
Em nosso caso, a etiologia traumatica não pode entrar em cogitação. O paciente já ha 9 annos se apresentou com manifestaçðes de seu mal. $\mathrm{Nada}$ encontrámos, senão estygmas de lues.

Embora todas as reacçð̃es de Wassermann, feitas após reactivação, tenham sido negativas, não se póde excluir a lues. A hypertrophia dos ganglios epitrochleanos, a tibialgia, retumbancia da segunda bulha aortica e o processo de aortite são elementos que dizem favor de um terreno luetico.

Cowford, estudando os aneurysmas cirsoides acha-os devidos a uma inflammação chronica da tunica externa da arteria, que obliteraria os vasa vasorum, alterando assim a elasticidade e a tonicidade das paredes arteriaes.

Reverdin explica a dilatação lenta e progressiva como devida á perda de tonicidade e elasticidade das tunicas arteriaes. E' essa dilatação lenta, progressiva e incessante que caracteriza a gravidade prognostica e que justifica a denominação de angioma maligno que se lhes dá.

Como symptomatologia dos aneurysmas cirsoides encontramos: calor local; tumor pulsatil, mólle, reductivel em parte, pela pressão e com fremito, ás vezes sopro, que tanto póde ser systolico ou diastolico, ou diastolosystolico, sendo mais intenso na systole. A compressão das arterias afferentes faz diminuir o tamanho do tumor. Ás vezes, o doente tem a sensação de formigamento e hypersensibilidade. As arterias se acham dilatadas; as veias ectasiadas e tortuosas. É esse conjuncto de vasos ectasiados, verdadeiro emaranhado de dilataçðes bosseladas, mal delimitadas, que nos chama logo a attenção. Veja-se para isso a gravura do diapositivo que projectámos. Reparem o tumor na raiz do annular; vejam a dilatação tortuosa das veias superficiaes, verdadeiras varizes. Pois bem: é esse aspecto, unido ao tumor arterial, com sua symptomatologia physica que nos auctoriza o diagnostico de aneurysma cirsoide.

Com o decorrer do tempo os tumores vão augmentando, as veias e arterias cada vez mais dilatadas, e não tarda que appareçam as hemorrhagias ao menor traumatismo. Bastou que o nosso doente soffresse uma inıervenção para gue, apezar da perfeita ligadura dos vasos, apparecessem hemorrhagias impressionantes para provirem da extremidade de mão.

Referindo-nos ao tratamento, veremos que as ligaduras sem extirpação do tumor não têm dado resultado. Egualmente têm sido debalde o emprego da coagulação, electrolyse, cauterisação e da radiumtherapia. Em grande numero de casos de aneurysmas cirsoides das porçóes terminaes dos membros, a amputaçáo se impóe.

Em nosso caso, o criterio tem sido o mais conservador possivel. Talvez, se a isso obrigar a evolução do caso, se resolva um golpe decisivo, qual seja a ligadura da sub-clavia, o que parece hoje pouco
viavel. 
Veremos ainda que os casos de recidiva não são raros.

O nosso paciente, como dissemos, tem experimentado melhoras. Náo poderemos porém prever que evolução terá o caso. Cremos não incorrer em grave erro, fazendo-lhe um prognostico sombrio, não pelo aneurysma em si, mas devido á aortite e á dilatação da sub-clavia, que vêm complicar seriamente o problema.

Cumpre-nos ainda notar uma cousa interessante: na radiographia da mão direita, tirada hoje, nota-se ao nivel da diaphyse dos $2.0^{\circ}$ e $3.0^{\circ}$ metacarpianos um processo de osteite condensante. Mauclaire chamou a attenção para a imagem radiologica de um seu caso, em que se notava hypercalcificação e espessamento do metacarpiano, proximo ao aneurysma cirsoide.

Quanto ao processo de osteoporose visto na radiographia de hoje, elle existe ha varios annos, contorme relatorio radiologico do Dr. Nicolau Scaff em exame radiographico anterior. 